\title{
COVID-19 and Sex-/Gender-Specific Differences: Understanding the Discrimination
}

\author{
Ariunzaya Amgalan, BS ${ }^{1}$ Ann Kinga Malinowski, MD, \\ ${ }^{1}$ Georgetown University School of Medicine, Washington, \\ District of Columbia \\ 2 Division of Maternal Fetal Medicine, Department of Obstetrics and \\ Gynecology, Lunenfeld-Tanenbaum Research Institute, Mount Sinai \\ Hospital, University of Toronto, Toronto, Ontario, Canada \\ 3 Department of Biomedical and Molecular Sciences, School of \\ Medicine, Queen's University, Kingston, Ontario, Canada \\ ${ }^{4}$ School of Baccalaureate Nursing, St. Lawrence College, \\ Kingston, Ontario, Canada
}

Semin Thromb Hemost 2021;47:341-347.

Coronavirus disease in 2019 (COVID-19), as caused by severe acute respiratory syndrome coronavirus 2 (SARS-CoV-2), has been associated with significant morbidity and mortality worldwide. Although SARS-CoV-2 primarily targets the respiratory system, it can cause various hematological and hemostatic derangements, most notably coagulopathies in severe cases. ${ }^{1,4}$ Thrombocytopenia and elevations in fibrinogen and D-dimer have been reported to be prognostic indicators of COVID-19 severity and/or mortality. ${ }^{2,4}$ Changes in hemostatic parameters correlate with parallel rises in inflammatory markers such as cytokines and C-reactive protein (CRP). ${ }^{4}$ Key mechanisms for SARS-CoV-2-induced coagulopathy include severe lung injury, alterations in the renin-angiotensin-aldosterone system (RAAS), and overactivation of the immune inflammatory pathways. 3,4

Of relevance to the current commentary, certain demographic and clinical factors, such as older age and preexisting comorbid conditions, can increase the risk of more severe infections. ${ }^{5,6}$ The number of COVID-19 cases is similar among males and females, as evidenced by data from over 700,000 confirmed COVID-19 cases collected by the World Health Organization (WHO). ${ }^{7}$ However, a recent meta-analysis suggests that men are more likely to experience severe disease and mortality compared with women. ${ }^{8}$ Yet, it is unclear whether the disparities in COVID-19 clinical outcomes are due to underlying sex-based biologic differences or gender-based behavioral differences. Exploration of the sex- and gender-based differences in SARS CoV-2 infection is vital, as these may carry potential implications for disease progression, outcome severity, vaccine response, therapeutic intervention and effectiveness, recruitment of males and/or

published online September 3, 2020
Issue Theme Maintaining Hemostasis and Preventing Thrombosis in COVID-19 -Part II; Guest Editors: Emmanuel J. Favaloro, PhD, FFSc (RCPA) and Giuseppe Lippi, MD.

Address for correspondence Maha Othman, MD, PhD, Department of Biomedical and Molecular Sciences, School of Medicine, Queen's University, Kingston, ON K7L 3N6, Canada

(e-mail: othman@queensu.ca).

females to clinical research studies, as well as identification of novel therapies for use in both sexes. In this report, we highlight those differences based on available evidence, attempt to explore and discuss possible underlying reasons, and provide our views for future research.

\section{COVID-19 and Sex Differences}

While males and females are both equally susceptible to COVID-19 infection, males are at increased risk for severe disease progression and poor outcomes. The Chinese Center for Disease Control and Prevention (CDC) analyzed 44,672 confirmed cases of COVID-19 and reported that the mortality rate in men (2.8\%) was nearly double that of women (1.7\%). ${ }^{9,10}$ Similar trends of greater COVID-19 severity and mortality in men compared with women were observed in reports from other countries. As of May 20, 2020, in 39 of 41 countries for which sex-disaggregated data are available, males were more likely to die from COVID-19 than females, ${ }^{11}$ highlighting a 2:1 male to female death ratio (MFDR) in most. ${ }^{11,12}$ In Italy, men comprised approximately $70 \%$ of COVID- 19 deaths ${ }^{13}$ and the MFDR was 3:1 in patients over 70 years of age, ${ }^{14}$ while Thailand had a MFDR of 2.8. ${ }^{11}$ Similarly, a case series of 5,700 patients hospitalized with COVID-19 in the New York City area found that the mortality rates were consistently higher in males, compared with females, across every age group above 20 years. ${ }^{15}$ Italy likewise reported higher mortality rates in men over 40 years of age. ${ }^{16}$

In terms of hospitalizations, reports from the United States (U.S.) CDC and Italy showed that men comprised more than half of COVID-19 hospitalizations. ${ }^{17,18}$ All 10 countries that

(c) 2020. Thieme. All rights reserved. Thieme Medical Publishers, Inc., 333 Seventh Avenue, 18th Floor, New York, NY 10001, USA
DOI https://doi.org/ 10.1055/s-0040-1715455. ISSN 0094-6176. 
currently provide COVID-19 admission rates by sex reported higher hospitalization rates in males than in females, ${ }^{11}$ with males comprising at least $61 \%$ of all COVID-19-related ICU admissions in these countries. ${ }^{11}$ Furthermore, across Europe, men constituted $73 \%$ of all COVID-19-related ICU admissions. ${ }^{16}$ A meta-analysis of 206,128 reported cases of COVID-19 worldwide found that male patients are at significantly higher risk of ICU admission (odds ratio [OR], 2.5) and death (OR, 1.6) compared with female patients. ${ }^{8}$ Other studies likewise consistently showed significant sex-specific differences in clinical characteristics and prognosis, with male sex as a risk factor for severe disease and mortality. ${ }^{16,19-22}$

\section{Potential Causes of Sex and Gender Differences in COVID-19}

This striking support for a male bias toward worse clinical outcomes in the COVID-19 pandemic demonstrated by the global epidemiologic data deserves investigation of the mechanisms underlying these sex- and perhaps genderbased differences. There are multiple plausible explanations, including (1) sex-specific biological differences (differences in the immune or inflammatory response, genetic profile, hormone types and levels, and differential expression of angiotensin-converting enzyme 2 [ACE2], the receptor for SARS CoV-2); (2) gender-specific behavioral or lifestyle differences; and/or (3) differences in underlying comorbid conditions. -Fig. 1 provides a summary of those potential explanations.

\section{The Potential Role of the X-Chromosome}

Known to carry the largest number of immune-related genes in the human genome, the $\mathrm{X}$ chromosome confers females a significant immunological advantage over males. ${ }^{23-25}$ Years of evidence have shown that compared with males, females typically mount stronger antibody and cell-mediated immune responses than males. ${ }^{26-29}$ Male susceptibility to poorer health outcomes is evident from the fetal period through adulthood. ${ }^{23,24,30} \mathrm{X}$-linked genes, X-linked micro-RNAs, female mosaicism, and heterogeneity or errors in X chromo- some inactivation may result in sex-specific immunological differences. $^{23,25,31}$ Fetal-placental programming, genetic variation, and sex hormones can play a role in shaping the sex-specific innate and adaptive immune inflammatory responses. ${ }^{23,24,30,32-35}$ In support of this, a study analyzing serum from 331 hospitalized patients found that most female patients with severe COVID-19 had more than $100 \mathrm{AU} / \mathrm{mL}$ of SARS-CoV-2 IgG antibodies, while most male patients had less than $100 \mathrm{AU} / \mathrm{mL}^{36}$ Additionally, females generated a stronger $\operatorname{IgG}$ production early on in the disease course compared with male patients, which is consistent with preexisting literature. $^{36}$

\section{Sex Hormones}

The sex-specific differences in COVID-19 severity may, at least in part, be explained by sex hormones and their regulatory effects. Androgens, which are found in higher concentrations in males, upregulate transmembrane serine protease 2 (TMPRSS2), which primes the spike protein of SARS-CoV-2 and facilitates its entry into the host. ${ }^{37-40}$ In vitro studies have shown that camostat mesylate, an inhibitor of TMPRSS2, blocks SARS-CoV-2 infection of lung cells, and its potential for viral load reduction in early COVID-19 infection is currently being investigated. . $^{37,41}$

In general, estrogens are considered immunostimulatory, and thus may be protective in the context of COVID-19, while androgens and progesterone are relatively immunosuppressive. ${ }^{34}$ Previous studies have also demonstrated that sex hormones regulate cytokine levels and the RAAS. ${ }^{42-47}$ Yet at the same time, studies have found an association between lower testosterone levels and increased inflammatory cytokines, ${ }^{46}$ and postulated that a reduction of testosterone in older men may be responsible for their increased vulnerability to severe disease, as well as to increased risk of both transfer to ICU and mortality. ${ }^{48}$ Similarly in females, reduced estrogen levels following menopause may explain the increased infection risk that older women have compared with the risk observed in younger women. In animal studies of SARS-CoV, ovariectomy or blockage of estrogen receptors was associated with increased susceptibility to the infection

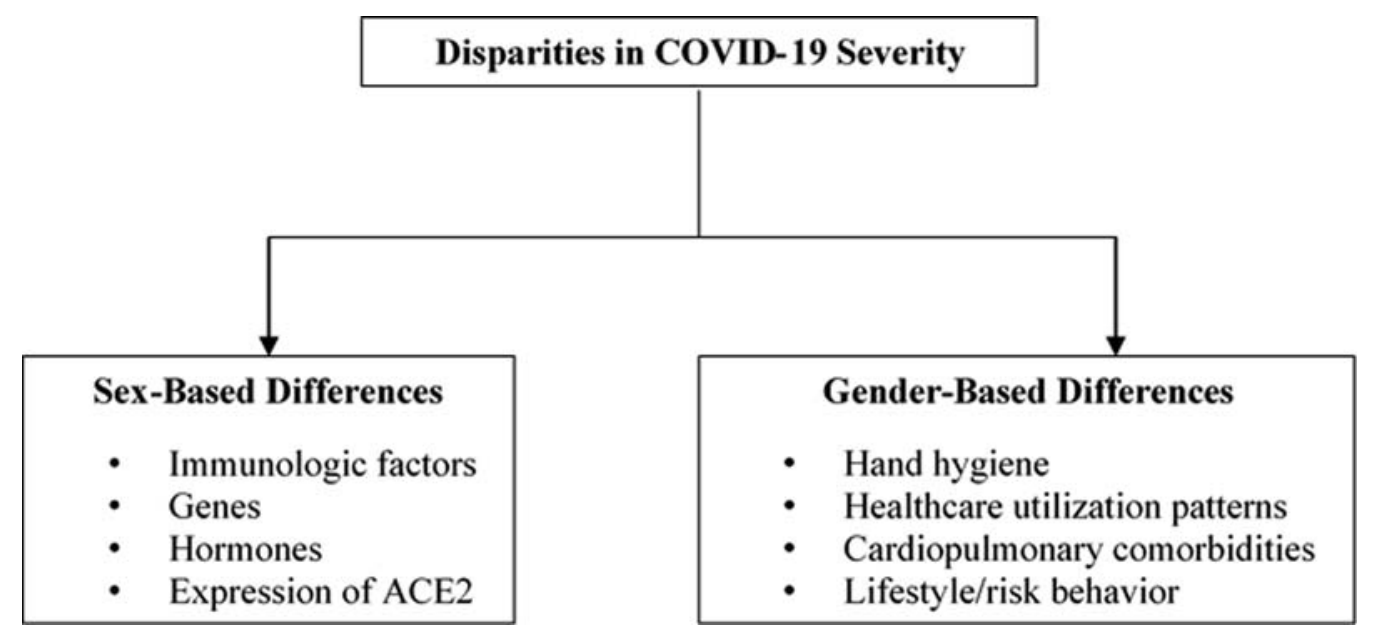

Fig. 1 Possible explanations for sex- and gender-based disparities in COVID-19 severity. ACE2, angiotensin-converting enzyme 2; COVID-19, coronavirus disease 2019. 
and increased mortality, implying that estrogen signaling may be protective for females. ${ }^{35,49}$

\section{Susceptibility in Pregnancy and Effects of Hormonal Contraception}

In contrast to other viral infections, including Middle East respiratory syndrome (MERS) and severe acute respiratory syndrome (SARS), which were characterized by high rates of severe morbidity and mortality during pregnancy, the COVID-19 infection does not appear to result in disproportional morbidity and/or mortality in pregnant women in comparison to the general population thus far. ${ }^{5,50}$

This may be explained by the fact that a significant proportion of morbidity and mortality in COVID-19 has been ascribed to cytokine storm syndrome, an aberrant immune response to SARS-CoV-2, ${ }^{51}$ a response which is immune in origin. The immunomodulatory actions of estrogen and progesterone are well established, ${ }^{52}$ and both play an important role in the modulation of the expression of Th1 and Th2 cytokines. ${ }^{53}$ These effects may contribute to the relatively mild course of COVID-19 in the majority of pregnant patients, whose estrogen and progesterone levels are elevated, and is supported by a recent report describing that $88 \%$ of women testing positive for SARS-CoV-2 on admission for delivery had no symptoms at presentation. ${ }^{54}$

Given the immunostimulatory effects of estrogen, the use of hormonal contraceptive pills may likewise be protective for females. For instance, hormonal contraception has been shown to reduce the susceptibility to HIV in females aged $<25$ years. ${ }^{55}$ The fact that as many as three quarters of reproductive age women use oral contraceptives at some point in their lives ${ }^{56}$ may thus in part explain some of the sex-based differences in COVID-19 severity. Observation of these effects in females has led one author to propose the extension of these potential hormonal modulating effects to males, by prescribing a fixed dose oral contraceptive pill as an adjunct to COVID-19 treatment. ${ }^{57,58}$ A clinical trial is currently underway to investigate if an estrogen patch can reduce disease severity in men and older postmenopausal women with COVID-19 infection. ${ }^{59}$

\section{Variation in ACE2 Expression}

It is well known that ACE2, the natural SARS-CoV-2 receptor, is integral to the pathophysiology of COVID-19. ACE2 is found in various organ systems throughout the body, and it has two different functional forms: transmembrane and soluble. ${ }^{60}$ SARS-CoV-2 uses the transmembrane form as a receptor for host cell entry. ${ }^{60}$ The soluble ACE2 lacks the transmembrane domain, and may act as a competitive interceptor, inhibiting the entry of SARS-CoV-2 and other coronaviruses. ${ }^{60}$ A recent in vitro study demonstrated that ACE2 fused to immunoglobulin potently neutralized SARS-CoV-2. ${ }^{61}$

The gene for ACE2 is located on the X chromosome, ${ }^{62}$ which means that the double $X$ chromosome in females may be protective, as heterozygous females can have a mosaic advantage while males are hemizygous. ${ }^{63}$ Furthermore, animal studies have revealed sexual dimorphism in ACE2 activity. ${ }^{64}$ However, data from human studies on whether higher or lower levels of ACE2 are more protective are conflicting, and controversy persists regarding expression of ACE2 in different subpopulations. For instance, Swärd et al observed that males expressed higher serum levels of soluble ACE2 than females, with differences becoming more pronounced with age, although the sample included only pediatric and adolescent patients up to a mean age of 23.5 years. ${ }^{65}$ Contrary to this study, Chen et al found significantly higher ACE2 expression in Asian females, with the highest levels observed in East Asian females, compared with males and other ethnic groups. ${ }^{66}$ They also noted that ACE2 expression decreased with increasing age and in the presence of certain inflammatory cytokines, in particular interleukin (IL)-2 and IL-7. ${ }^{66}$ Given the findings of higher ACE2 levels in females and younger individuals, it is possible that higher baseline ACE2 levels confer an advantage by counteracting the depletion of ACE2 by SARS-CoV-2, though this hypothesis will need to be tested in future studies. ${ }^{63,66}$

SARS-CoV-2 decreases ACE2 levels, leading to accumulation of angiotensin II, aldosterone, and ACE, shifting the hemostatic balance toward a hypercoagulable and hypofibrinolytic state, further characterized by decreased tissue plasminogen activator (tPA) to plasminogen activator inhibitor-1 (PAI-1) ratio. ${ }^{3}$ Angiotensin II directly increases PAI-1 expression from endothelial cells and from adipocytes. ${ }^{3}$ Aldosterone increases ACE expression, which increases bradykinin breakdown, inhibiting bradykinin-mediated increase in tPA. ${ }^{3}$ Thus, high baseline ACE2 levels could be protective, as they may mitigate the procoagulant effects of angiotensin II, aldosterone, and ACE, and in doing so attenuate the risk of severe COVID-19. This is supported by previous studies which demonstrated that recombinant ACE2 can rapidly decrease angiotensin II and IL-6 levels, ${ }^{67}$ and can reduce the viral load of SARS-CoV-2. ${ }^{68}$ Interestingly, abundant ACE2 expression has likewise been noted within the human placenta: mainly within the syncytiotrophoblast, cytotrophoblast, endothelium, and vascular smooth muscle of the villi. ${ }^{69}$ Clarification of the potential links between placental ACE2 expression and SARS-CoV-2 susceptibility, disease severity in pregnancy, vertical transmission, and fetal outcomes require examination in larger studies.

\section{SARS CoV-2 Viral Tropism}

The genetic characteristics of the organisms may play a role in virus tropism and this seems to vary by age and sex. Spanish influenza killed proportionately more young males compared with other influenza viruses. ${ }^{70}$ Poliomyelitis and hepatitis $C$ showed higher male mortality in all ages, while smallpox, measles, rubella, hepatitis B, and influenza showed higher female mortality. ${ }^{71}$ The mechanisms of varying tropism remain unknown. Studies to uncover the characteristics of viral tropism of SARS CoV-2 are yet to be conducted.

\section{Gender-Based Behavioral/Lifestyle Differences}

Aside from biological factors, gender-based behavioral and lifestyle differences may contribute to the male predisposition for more severe disease. Smoking is a well-known risk factor for cardiopulmonary comorbidities through alteration of the RAAS homeostasis, ${ }^{72}$ thereby heightening vulnerability to poor clinical outcomes. Globally, smoking is more common 
in men than in women. ${ }^{73}$ However, it is difficult to isolate the effect of smoking or any one comorbidity on disease prognosis. A meta-analysis of five studies did not find a statistically significant difference between active smoking and severity of COVID-19. ${ }^{74}$ The relationship between smoking and COVID19 is complex; while smoking upregulates ACE2, it is unclear whether this increases or decreases risk for COVID-19 severity. $^{75}$

Additional gender-based differences include the higher frequency with which females access medical care in comparison to males, and the greater likelihood that females comply with hand-hygiene practices. ${ }^{76-78}$ By contrast, males are more likely to engage in risky behavior, including activities that may compromise their health. ${ }^{76,79}$

\section{Concluding Remarks and Recommendations for Future Studies}

Worldwide epidemiological data show that sex and gender can be major drivers of risk for severe disease and mortality. While the prevalence of COVID-19 seems to be similar between the sexes, men appear to be at higher risk for severe infection and mortality. The sex-specific discrepancies seen in COVID-19 outcomes are not unique to this disease, as similar trends have been observed with many viral respiratory tract infections. ${ }^{26,35}$ The epidemics of SARS in 2002-2003 and MERS in 2012 also exhibited a male bias for more severe disease and mortality. ${ }^{35,73,80,81}$ Given that sex differences in disease outcomes exist, it is worth exploring the mechanisms mediating these differences. Sex is a biological variable, and consequently, differences in immunologic responses, genes, hormones, and the expression of ACE2 may be driving a male bias toward more severe COVID19 infection and mortality. It is also important to acknowledge that gender-based differences in behavior and lifestyle habits may also contribute to the disparities seen in disease manifestations.

Identifying and studying the effects of sex and gender differences on COVID-19 susceptibility, disease severity, and mortality will help us evaluate vaccine responses and strategies, therapeutic intervention, recruitment decisions of males and/or females to clinical research studies, and identification of novel therapies for use in both sexes. In - Table 1, we provide suggestions for future studies to better understand the reasons for sex- or gender-based differences in COVID-19 severity and prognosis. For all future studies, sexand gender-disaggregated data are critical for understanding differences in risk and response to infection, and thereby for

Table 1 Recommendations for future studies on COVID-19

\begin{tabular}{|c|c|}
\hline & Recommendations for future studies \\
\hline \multicolumn{2}{|c|}{ Sex-based differences } \\
\hline $\begin{array}{l}\text { Immunologic } \\
\text { factors }\end{array}$ & $\begin{array}{l}\text { - Compare cytokine levels in males versus females with COVID-19 of similar disease severity } \\
\text { - Compare immunoglobulin levels by sex and disease outcomes }\end{array}$ \\
\hline Genes & - Determine genetic markers that may predict increased susceptibility to severe COVID-19 \\
\hline Hormones & $\begin{array}{l}\text { - Determine the effect(s) of hormones and their receptors on ACE2 and TMPRSS2 levels, and in } \\
\text { general on SARS-CoV-2 entry, replication, and spread through in vitro studies } \\
\text { - Measure hormonal levels by sex and age groups and correlate findings with severity of COVID-19 } \\
\text { - Investigate the effect of hormonal contraception on susceptibility to COVID-19 }\end{array}$ \\
\hline $\begin{array}{l}\text { Expression } \\
\text { of ACE2 }\end{array}$ & $\begin{array}{l}\text { - Analyze variation in ACE2 expression by sex and ethnic groups } \\
\text { - Correlate sex-specific variation in ACE2 expression with severity of COVID-19 }\end{array}$ \\
\hline Pregnancy & $\begin{array}{l}\text { - Examine differences in susceptibility to COVID-19 in pregnant vs. nonpregnant individuals } \\
\text { - Explore placental expression of ACE2 and its links to SARS-CoV-2 susceptibility, vertical transmission, } \\
\text { as well as maternal and fetal outcomes }\end{array}$ \\
\hline \multicolumn{2}{|c|}{ Gender-based differences } \\
\hline Handwashing & - Survey relevant groups to assess differences in handwashing practices, patterns, and attitudes \\
\hline $\begin{array}{l}\text { Healthcare } \\
\text { utilization } \\
\text { patterns }\end{array}$ & - Assess factors affecting decisions regarding when medical care is accessed based on sex and gender \\
\hline $\begin{array}{l}\text { Lifestyle/ } \\
\text { risk behavior }\end{array}$ & - Assess other lifestyle differences, including risk behaviors \\
\hline \multicolumn{2}{|c|}{ Sex- or gender-based differences } \\
\hline $\begin{array}{l}\text { Comorbid } \\
\text { conditions }\end{array}$ & - Record frequency, type, and number of comorbid conditions by sex \\
\hline Therapy & $\begin{array}{l}\text { - Examine the role of RAAS medications in suppressing COVID-19 } \\
\text { - Devise clinical trials to evaluate safety and efficacy of camostat mesylate for treatment of COVID-19 } \\
\text { - Determine if there are sex-specific differences in response to various therapies for COVID-19 }\end{array}$ \\
\hline
\end{tabular}

Abbreviations: ACE2, angiotensin-converting enzyme 2; COVID-19, coronavirus disease 2019; SARS-CoV-2, severe acute respiratory syndrome coronavirus 2; RAAS, renin-angiotensin-aldosterone system; TMPRSS2, transmembrane serine protease 2. 
guiding effective targeted prevention and management of disease.

\section{Conflict of Interest}

None declared.

\section{References}

1 Becker RC. COVID-19 update: COVID-19-associated coagulopathy. J Thromb Thrombolysis 2020;50(01):54-67

2 Lippi G, Favaloro EJ. D-dimer is associated with severity of coronavirus disease 2019: a pooled analysis. Thromb Haemost 2020;120(05):876-878

3 Henry BM, Vikse J, Benoit S, Favaloro EJ, Lippi G. Hyperinflammation and derangement of renin-angiotensin-aldosterone system in COVID-19: a novel hypothesis for clinically suspected hypercoagulopathy and microvascular immunothrombosis. Clin Chim Acta 2020;507:167-173

4 Amgalan A, Othman M. Hemostatic laboratory derangements in COVID-19 with a focus on platelet count. Platelets 2020;31(06): 740-745

5 Knight M, Bunch K, Vousden Net al.. Characteristics and outcomes of pregnant women admitted to hospital with confirmed SARSCoV-2 infection in the UK: national population based cohort study. BMJ 2020;369:m2107

6 Kayem G, Lecarpentier E, Deruelle Pet al. A snapshot of the COVID19 pandemic among pregnant women in France. J Gynecol Obstet Hum Reprod 2020;49(07):101826

7 World Health Organization. SUBJECT IN FOCUS: WHO Global CaseBased Surveillance for Human Infection with Coronavirus Disease (COVID-19).; 2020. Available at: https://www.who.int/docs/ default-source/coronaviruse/situation-reports/20200418-sitrep89-covid-19.pdf?sfvrsn=3643dd38_2. Accessed May 23, 2020

8 Peckham H, de Gruijter N, Raine C, et al. Sex-bias in COVID-19: a meta-analysis and review of sex differences in disease and immunity. Nat Commun 2020 (epub ahead of print). Doi:10.21203/RS.3.RS-23651/V1

9 The Novel Coronavirus Pneumonia Emergency Response Epidemiology Team. The epidemiological characteristics of an outbreak of 2019 novel coronavirus diseases (COVID-19)-China, 2020. China CDC Weekly 2020;2(08):113-122

$10 \mathrm{Wu} \mathrm{Z,} \mathrm{McGoogan} \mathrm{JM.} \mathrm{Characteristics} \mathrm{of} \mathrm{and} \mathrm{important} \mathrm{lessons}$ from the coronavirus disease 2019 (COVID-19) outbreak in China: summary of a report of 72314 cases from the Chinese Center for Disease Control and Prevention. JAMA 2020;323(13):1239-1242

11 COVID-19 sex-disaggregated data tracker - Global Health 50/50. Available at: https://globalhealth5050.org/covid19/sex-disaggregated-data-tracker/\#1587645651236-8a62beb3-4a03. Accessed May 23, 2020

12 Michelozzi P, de'Donato F, Scortichini M, et al. Mortality impacts of the coronavirus disease (COVID-19) outbreak by sex and age: rapid mortality surveillance system, Italy, 1 February to 18 April 2020. Euro Surveill 2020;25(19):2000620

13 Di Lorenzo G, Di Trolio R. Coronavirus disease (COVID-19) in Italy: analysis of risk factors and proposed remedial measures. Front Med (Lausanne) 2020;7:140

14 Di Stadio A, Ricci G, Greco A, de Vincentiis M, Ralli M. Mortality rate and gender differences in COVID-19 patients dying in Italy: a comparison with other countries. Eur Rev Med Pharmacol Sci 2020;24(08):4066-4067

15 Richardson S, Hirsch JS, Narasimhan M, et al; The Northwell COVID19 Research Consortium. Presenting characteristics, comorbidities, and outcomes among 5700 patients hospitalized with COVID-19 in the New York City area. JAMA 2020;323(20):2052-2059

16 Serge R, Vandromme J, Charlotte M. Are we equal in adversity? Does COVID-19 affect women and men differently?. Maturitas 2020;138:62-68
17 Grasselli G, Zangrillo A, Zanella A, et al; COVID-19 Lombardy ICU Network. Baseline characteristics and outcomes of 1591 patients infected with SARS-CoV-2 admitted to ICUs of the Lombardy region, Italy. JAMA 2020;323(16):1574-1581

18 Garg S, Kim L, Whitaker M, et al. Hospitalization rates and characteristics of patients hospitalized with laboratory-confirmed coronavirus disease 2019 - COVID-NET, 14 states, March 1-30, 2020. MMWR Morb Mortal Wkly Rep 2020;69 (15):458-464

19 Meng Y, Wu P, Lu W, et al. Sex-specific clinical characteristics and prognosis of coronavirus disease-19 infection in Wuhan, China: a retrospective study of 168 severe patients. PLOS Pathog 2020;16 (04):e1008520

20 Li X, Xu S, Yu M, et al. Risk factors for severity and mortality in adult COVID-19 inpatients in Wuhan. J Allergy Clin Immunol 2020;146(01):110-118

21 Lechien JR, Chiesa-Estomba CM, Place S, et al; COVID-19 Task Force of YO-IFOS. Clinical and epidemiological characteristics of 1420 European patients with mild-to-moderate coronavirus disease 2019. J Intern Med 2020;288(03):335-344

22 Luo H, Lie Y, Prinzen FW. Surveillance of coronavirus disease 2019 in general population using an online questionnaire: a report from 18161 respondents in China (preprint). JMIR Public Health Surveill 2020;6(02):e18576

23 Libert C, Dejager L, Pinheiro I. The X chromosome in immune functions: when a chromosome makes the difference. Nat Rev Immunol 2010;10(08):594-604

24 Schurz H, Salie M, Tromp G, Hoal EG, Kinnear CJ, Möller M. The X chromosome and sex-specific effects in infectious disease susceptibility. Hum Genomics 2019;13(01):2

25 Conti P, Younes A. Coronavirus COV-19/SARS-CoV-2 affects women less than men: clinical response to viral infection. J Biol Regul Homeost Agents 2020;34(02):339-343

26 vom Steeg LG, Klein SL. SeXX matters in infectious disease pathogenesis. PLoS Pathog 2016;12(02):e1005374

27 Amadori A, Zamarchi R, De Silvestro G, et al. Genetic control of the CD4/CD8 T-cell ratio in humans. Nat Med 1995;1(12):1279-1283

28 Villacres MC, Longmate J, Auge C, Diamond DJ. Predominant type $1 \mathrm{CMV}$-specific memory T-helper response in humans: evidence for gender differences in cytokine secretion. Hum Immunol 2004; 65(05):476-485

29 Hewagama A, Patel D, Yarlagadda S, Strickland FM, Richardson BC. Stronger inflammatory/cytotoxic T-cell response in women identified by microarray analysis. Genes Immun 2009;10(05): 509-516

30 Buckberry S, Bianco-Miotto T, Bent SJ, Dekker GA, Roberts CT. Integrative transcriptome meta-analysis reveals widespread sexbiased gene expression at the human fetal-maternal interface. Mol Hum Reprod 2014;20(08):810-819

31 Pinheiro I, Dejager L, Libert C. X-chromosome-located microRNAs in immunity: might they explain male/female differences? The $\mathrm{X}$ chromosome-genomic context may affect $\mathrm{X}$-located miRNAs and downstream signaling, thereby contributing to the enhanced immune response of females. BioEssays 2011;33 (11):791-802

32 Chamekh M, Deny M, Romano M, et al. Differential susceptibility to infectious respiratory diseases between males and females linked to sex-specific innate immune inflammatory response. Front Immunol 2017;8:1806

33 Sundrani DP, Roy SS, Jadhav AT, Joshi SR. Sex-specific differences and developmental programming for diseases in later life. Reprod Fertil Dev 2017;29(11):2085-2099

34 Moulton VR. Sex hormones in acquired immunity and autoimmune disease. Front Immunol 2018;9:2279

35 Kadel S, Kovats S. Sex hormones regulate innate immune cells and promote sex differences in respiratory virus infection. Front Immunol 2018;9:1653 
36 Zeng F, Dai C, Cai P, et al. A comparison study of SARS-CoV-2 IgG antibody between male and female COVID-19 patients: a possible reason underlying different outcome between sex. J Med Virol 2020:25989

37 Hoffmann M, Kleine-Weber H, Schroeder S, et al. SARS-CoV-2 cell entry depends on ACE2 and TMPRSS2 and is blocked by a clinically proven protease inhibitor. Cell 2020;181(02):271-280.e8

38 Sungnak W, Huang N, Bécavin C, et al; HCA Lung Biological Network. SARS-CoV-2 entry factors are highly expressed in nasal epithelial cells together with innate immune genes. Nat Med 2020;26(05):681-687

39 TMPRSS2 transmembrane serine protease 2 [Homo sapiens (human)] - Gene - NCBI. Available at: https://www.ncbi.nlm. nih.gov/gene/7113. Accessed May 25, 2020

40 Matsuyama S, Nao N, Shirato K, et al. Enhanced isolation of SARSCoV-2 by TMPRSS2-expressing cells. Proc Natl Acad Sci U S A 2020;117(13):7001-7003

41 Camostat Mesylate in COVID-19 Outpatients - Full Text View ClinicalTrials.gov. Available at: https://clinicaltrials.gov/ct2/show /NCT04353284. Accessed June 5, 2020

42 Brosnihan KB, Hodgin JB, Smithies O, Maeda N, Gallagher P. Tissue-specific regulation of ACE/ACE2 and AT1/AT2 receptor gene expression by oestrogen in apolipoprotein $\mathrm{E} /$ oestrogen receptor- $\alpha$ knock-out mice. Exp Physiol 2008;93(05):658-664

43 Bukowska A, Spiller L, Wolke C, et al. Protective regulation of the ACE2/ACE gene expression by estrogen in human atrial tissue from elderly men. Exp Biol Med (Maywood) 2017;242(14):1412-1423

44 Mohamad N-V, Wong SK, Wan Hasan WN, et al. The relationship between circulating testosterone and inflammatory cytokines in men. Aging Male 2019;22(02):129-140

45 Shivers KY, Amador N, Abrams L, Hunter D, Jenab S, QuiñonesJenab V. Estrogen alters baseline and inflammatory-induced cytokine levels independent from hypothalamic-pituitary-adrenal axis activity. Cytokine 2015;72(02):121-129

46 Bianchi VE. The anti-inflammatory effects of testosterone. J Endocr Soc 2018;3(01):91-107

47 La Vignera S, Cannarella R, Condorelli RA, Torre F, Aversa A, Calogero AE. Sex-specific SARS-CoV-2 mortality: among hormone-modulated ACE2 expression, risk of venous thromboembolism and hypovitaminosis D. Int J Mol Sci 2020;21(08):2948

48 Rastrelli G, Di Stasi V, Inglese F, et al. Low testosterone levels predict clinical adverse outcomes in SARS-CoV-2 pneumonia patients. Andrology 2020:12821

49 Channappanavar R, Fett C, Mack M, Ten Eyck PP, Meyerholz DK, Perlman S. Sex-based differences in susceptibility to severe acute respiratory syndrome coronavirus infection. J Immunol 2017;198 (10):4046-4053

50 Schwartz DA, Graham AL. Potential maternal and infant outcomes from (Wuhan) coronavirus 2019-nCoV infecting pregnant women: lessons from SARS, MERS, and other human coronavirus infections. Viruses 2020;12(02):194

51 Jose RJ, Manuel A. COVID-19 cytokine storm: the interplay between inflammation and coagulation. Lancet Respir Med 2020;8(06):e46-e47

52 Beagley KW, Gockel CM. Regulation of innate and adaptive immunity by the female sex hormones oestradiol and progesterone. FEMS Immunol Med Microbiol 2003;38(01):13-22

53 Salem ML. Estrogen, a double-edged sword: modulation of TH1and TH2-mediated inflammations by differential regulation of TH1/TH2 cytokine production. Curr Drug Targets Inflamm Allergy 2004;3(01):97-104

54 Sutton D, Fuchs K, D’Alton M, Goffman D. Universal screening for SARS-CoV-2 in women admitted for delivery. N Engl J Med 2020; 382(22):2163-2164

55 Leclerc PM, Dubois-Colas N, Garenne M. Hormonal contraception and HIV prevalence in four African countries. Contraception 2008;77(05):371-376
56 Rotermann M, Dunn S, Black A. Oral contraceptive use among women aged 15 to 49: results from the Canadian Health Measures Survey. Stat Canada 2015;26(10):21-28

57 Sanal MG. RE: Oral contraceptive pills may be better and safe in the management of COVID-19 than chloroquine derivatives!. CMAJ 2020;192(17):E450-E453

58 Juurlink DN. Safety considerations with chloroquine, hydroxychloroquine and azithromycin in the management of SARS-CoV-2 infection. CMAJ 2020;192(17):E450-E453

59 Estrogen Patch for COVID-19 Symptoms - Full Text View - ClinicalTrials.gov. Available at: https://clinicaltrials.gov/ct2/show/ NCT04359329. Accessed May 24, 2020

60 Batlle D, Wysocki J, Satchell K. Soluble angiotensin-converting enzyme 2: a potential approach for coronavirus infection therapy? Clin Sci (Lond) 2020;134(05):543-545

61 Lei C, Fu W, Qian K, et al. Potent neutralization of 2019 novel coronavirus by recombinant ACE2-Ig. bioRxiv 2020; Doi: org/ 10.1101/2020.02.01.929976

62 Patel SK, Velkoska E, Freeman M, Wai B, Lancefield TF, Burrell LM. From gene to protein-experimental and clinical studies of ACE2 in blood pressure control and arterial hypertension. Front Physiol 2014;5:227

63 Gemmati D, Bramanti B, Serino ML, Secchiero P, Zauli G, Tisato V. COVID-19 and individual genetic susceptibility/receptivity: role of ACE1/ACE2 genes, immunity, inflammation and coagulation. Might the double X-chromosome in females be protective against SARS-CoV-2 compared to the single X-chromosome in males? Int J Mol Sci 2020;21(10):E3474

64 Liu J, Ji H, Zheng W, et al. Sex differences in renal angiotensin converting enzyme 2 (ACE2) activity are $17 \beta$-oestradiol-dependent and sex chromosome-independent. Biol Sex Differ 2010;1 (01):6

65 Swärd P, Edsfeldt A, Reepalu A, Jehpsson L, Rosengren BE, Karlsson MK. Age and sex differences in soluble ACE2 may give insights for COVID-19. Crit Care 2020;24(01):221

66 Chen J, Jiang Q, Xia X, et al. Individual Variation of the SARS-CoV2 Receptor ACE2 Gene Expression and Regulation. Preprints; 2020. Available at: www.preprints.org. Accessed May 24, 2020

67 Khan A, Benthin C, Zeno B, et al. A pilot clinical trial of recombinant human angiotensin-converting enzyme 2 in acute respiratory distress syndrome. Crit Care 2017;21(01):234

68 Monteil V, Kwon $\mathrm{H}$, Prado $\mathrm{P}$, et al. Inhibition of SARS-CoV-2 infections in engineered human tissues using clinical-grade soluble human ACE2. Cell 2020;181(04):905-913.e7

69 Valdés G, Neves LAA, Anton L, et al. Distribution of angiotensin-(1$7)$ and ACE2 in human placentas of normal and pathological pregnancies. Placenta 2006;27(2-3):200-207

70 Noymer A, Garenne M. The 1918 influenza epidemic's effects on sex differentials in mortality in the United States. Popul Dev Rev 2000;26(03):565-581

71 Garenne M. Demographic evidence of sex differences in vulnerability to infectious diseases. J Infect Dis 2015;211(02):331-332

72 Oakes JM, Fuchs RM, Gardner JD, Lazartigues E, Yue X. Nicotine and the renin-angiotensin system. Am J Physiol Regul Integr Comp Physiol 2018;315(05):R895-R906

73 Elgendy IY, Pepine CJ. Why are women better protected from COVID-19: Clues for men? Sex and COVID-19. Int J Cardiol 2020; Doi: 10.1016/j.ijcard.2020.05.026 (epub ahead of print)

74 Lippi G, Henry BM. Active smoking is not associated with severity of coronavirus disease 2019 (COVID-19). Eur J Intern Med 2020; 75:107-108

75 Lippi G, Sanchis-Gomar F, Henry BM. Active smoking and COVID19: a double-edged sword. Eur J Intern Med 2020;77(00): 123-124

76 Walter LA, McGregor AJ. Sex- and gender-specific observations and implications for COVID-19. West J Emerg Med 2020;21(03): 507-509 
77 Suen LKP, So ZYY, Yeung SKW, Lo KYK, Lam SC. Epidemiological investigation on hand hygiene knowledge and behaviour: a crosssectional study on gender disparity. BMC Public Health 2019;19 (01):401

78 Johnson HD, Sholcosky D, Gabello K, Ragni R, Ogonosky N. Sex differences in public restroom handwashing behavior associated with visual behavior prompts. Percept Mot Skills 2003;97(3, Pt 1):805-810
79 Harris CR, Jenkins M. Gender differences in risk assessment: Why do women take fewer risks than men? Judgment Decision Making 2006;1(01):48-63

80 Karlberg J, Chong DSY, Lai WYY. Do men have a higher case fatality rate of severe acute respiratory syndrome than women do? Am J Epidemiol 2004;159(03):229-231

81 Jin J-M, Bai P, He W, et al. Gender differences in patients with COVID19: focus on severity and mortality. Front Public Health 2020;8:152 